\title{
New Trends in Scientific and Technological revolution (STR) and Transformation of Science and Education Systems in the Paradigm of Sustainable Development
}

\author{
Olena Yakovleva ${ }^{1^{*}}$, Vadym Slyusar ${ }^{2}$, Olga Kushnir $^{3}$ and Antonina Sabovchyk ${ }^{4}$ \\ ${ }^{1}$ Doctor of Philosophical Sciences, Professor, Rector Kyiv Institute of Business and Technology, \\ Kyiv, Ukraine \\ ${ }^{2}$ Doctor of Sciences (Philosophy), Associate Professor, Professor of the Department of Philosophy \\ and Political Science, Zhytomyr Ivan Franko State University, Zhytomyr, Ukraine \\ ${ }^{3} \mathrm{PhD}$ in Philosophical Sciences, Associate Professor, Vice-rector Kyiv Institute of Business and \\ Technology, Kyiv, Ukraine \\ ${ }^{4}$ Candidate of Law, Associate Professor, Associate Professor of the Department of Civil Law and \\ Procedure, Uzhhorod National University, Uzhhorod, Ukraine
}

\begin{abstract}
Education and science play a key role in the vision and development of a fair, peaceful and sustainable society (global, continental, regional and national). Education is one of the crucial preconditions for the implementation of the UN global strategy "Transforming our world: the 2030 Agenda for Sustainable Development" ("Agenda 2030"). Agenda 2030 sets practical challenges for governments to transform the education system (Education for Sustainable Development).

Developments in the field of artificial intelligence (AI), robotics and intelligent systems are developing rapidly right now, purely now bring benefits (and, at the same time - probable danger and harm), directly now - significantly determine our existence - and will soon determine even more.

When universities argue that 4IR should be given strong and close attention, it means that they can no longer rely only on traditional forms of human thinking and imagination, but also need thinking that depends on algorithmic computations of machines or forms of technology. In this sense, 4IR has changed not only what we do and how we do it, but also who we have become.

The mission of the universities of the XXI century is to form a developed personality, a person of high cultural level, who can act in a situation characterized by significant environmental risks.

Educational institutions must be transformed and improved as institutions that must create and strengthen a safe, non-violent, inclusive and effective learning environment for all members of society. Which, in the end, will help to achieve success in cooperation at all levels - both in education and science, and in society in general.
\end{abstract}

\section{Introduction}

Universities in particular and educational institutions in general should learn to work together in partnership, develop sustainable development skills, critical thinking, share responsibilities between students and the entire educational team, and in such way educational institutions can be examples of sustainable lifestyles [1].

\footnotetext{
* Corresponding author:vivonapnuivo@gmail.com
} 
The process of democratization of institutions of society, education and science can effectively change decision-making in the field of socio-economic activities, education and science, which consists of two relatively independent factors:

- on the one hand, - from the community of citizens, educators, scientists as a community with the ability to self-organization and self-government,

- on the other hand - from the structures and bodies of social and administrative management, which carries out the will of the state and society, but capable of transferring part of power in self-government relations.

Given that the phenomena of integration and internationalization in the context of globalization are growing rapidly, and their properties are determined by the laws dictated by the prevailing trend of global development, these phenomena are especially important for small countries and those embarking on intensive development or looking for models of economic, social, scientific and educational intensification and institutional transformations for sustainable development of society in the context of internationalization of higher education and science.

Teaching and acquiring knowledge take place in society, scientific and technological space. Analysis of large-scale trends is necessary for decision-making that will ensure the construction of a sustainable and ready for the future educational environment.

\section{Research methodology}

The rapid gradual globalization is facilitated by the rapid development of information and communication technologies and the idea of a network-based way of organizing social activity. It should be applied integrative philosophical conceptualization and scientific synthesis of existing concepts and theories of the relevant direction.

The process of education, teaching and acquiring knowledge takes place in society, concentrating in its scientific and technological spheres.

Analyzing of the global and large-scale trends is essential for decision making that will ensure the construction of a sustainable environment and future-ready ecological education.

In many countries, adults have inadequate complex digital information management skills, therefore, governments and employers must seriously address issues relating to not only the continuity of education, but also to its comprehensiveness.

Robotics and intelligent systems are rapidly evolving directly now, especially today, when it brings substantial benefit (and possibly - some dangers and damage), and now it significantly defines our being - and it will soon be even more essential to determine. The robots are becoming more and more like a human, and a person learns to interact with them, constantly improving them not only externally, but also internally.

\section{Result}

\subsection{Problem}

Developments in the field of artificial intelligence (AI), robotics and intelligent systems are developing rapidly right now, purely now bring benefits (and, at the same time probable danger and harm), directly now - significantly determine our existence - and will soon determine even more [2].

Robots are becoming more and more like humans, and man is learning to interact with them, constantly improving them not only externally but also internally. In Japan, the speech robot - android Pepper - is officially accepted to high school in the Japanese city of Waseda. Pepper learns with children, which are given the opportunity to use a unique chance to communicate with the robot. Scientists and educators believe that such communication will be useful to them in the future. According to the developers, the robot is equipped with a large number of cameras and sensors that allow it to recognize and 
respond to almost the entire range of human emotions: joy, sadness, fear, excitement, irritation. It also has the ability to self-learning.

Earlier in Japan, for the first time in history, a cyber android named NAO was included in the staff of Japan's largest bank The Bank of Tokyo-Mitsubishi UFJ. NAO is a humanlike robots developed by SoftBank, an information technology corporation. NAOs are easy to move and gesture with manipulators, with the help of cameras and sound sensors they respond to visitors, answer questions and can support thematically diverse conversations in many languages [3].

Modern social designers should pay special attention to the latest technological trends in innovation and be able to predict the future. And for this, first of all, many scientists recommend reading science fiction, because exactly this literature stimulates brain activity, develops imagination and thinking.

It is no coincidence that in China now more attention is paid to science fiction. In an interview with The Guardian, Neil Gaiman said that the Chinese interest in science fiction was because they were brilliant at imitating, but were bad with innovation, invention and had problems with imagination [4].

As a result, the Chinese sent their representatives to the United States - to Apple, Microsoft, Google - and asked people who invent the future to tell about themselves. As a result, it turned out that they got used to read science fiction in a childhood. Focusing on solid science fiction in China correlates greatly with the victories of Chinese students in international tests and competitions. As it was revealed, the Chinese have begun actively shape their image of the future. The desired positive future. However, the fear of artificial intelligence (AI) was born in the 1960s thanks to Irwin Hood, a British mathematician and cryptographer who worked with Alan Turing on the hacking of the German Enigma encryption machine during World War II.

Hood's thoughts on AI led him to think of a super-intelligent machine that, through selflearning, could surpass human intelligence, no matter how intelligent it was. When this machine starts building similar machines, there will be an "intellectual explosion" - this will be the last invention that a person needed to make.

In 1965, he created the concept known as the "intellectual explosion" or "technological singularity", which suggests the possible emergence of superhuman intelligence.

Technological singularity - a hypothetical moment in the future, when technological development becomes uncontrollable and irreversible, which causes radical changes (singularity) in the nature of human civilization. "Technological singularity" in futurology is an explosive surge in the speed of scientific and technological progress, which is likely to occur due to the creation of artificial intelligence and machines capable of selfreproduction. A hypothetical moment, after which, according to supporters of this concept, technological progress will be so rapid and complex that it will be inaccessible.

The development of artificial intelligence (AI) has led to a very interesting phenomenon - the so-called deep fiction, or in English deepfake. This word comes from a combination of "deep learning", the method used in the formation of artificial intelligence, and "fiction" itself. And such an invention looks like a video plot where a real character commits an act that he did not commit, or says words that he did not utter. Then these fictions begin to walk on the Web, become viral memes and are part of an illusory reality that replaces the real reality

\subsection{Cause analysis}

But what if a super-intelligent machine one day realizes that it doesn't need a person and starts behaving like a Terminator - restricting people's rights and possibly killing? 
So, it is not surprising that Hood's ideas have become relevant again today. Is it strange that they were picked up by leading representatives of science and the IT industry?

"Let's define a super-intelligent machine as a machine that can far surpass all the intellectual activity of any person, no matter how intelligent it may be. Because machine design is one of these intellectual activities, a super-intelligent machine can create machines even better; then, of course, there would be an "explosion of intelligence" and the human mind would be far behind ... Thus, the first super intelligent machine is the last invention that man will ever need, provided that the machine is obedient enough to tell us how to keep it under control. Interestingly, outside of science fiction, this is so rarely talked about. Sometimes you should take science fiction seriously" [5].

"The development of completely artificial intelligence could bring the decline of the human era closer," said the famous physicist Stephen Hawking in 2014 [6].

"At first, unburdened machines will do most of the work for us. And it is good if we learn to manage them properly. But in a few decades, AI will develop to the point of concern," echoes Microsoft founder Bill Gates.

Tesla chief Elon Musk has gone even further, allocating billions of dollars to these issues and, in particular, donating millions of dollars to AI safety research at the Future of Life Institute [7] and comparing AI developers armed with holy water exorcists trying to tame the demon.

"I think the danger of AI is much bigger than even the danger of nuclear warheads," Musk said. "Because no one would suggest that we allow the whole world to simply build nuclear warheads freely if they want to, it would be madness."

Remember my words: AI is much more dangerous than nuclear weapons.

The global pandemic has posed unprecedented challenges to every aspect of interaction with society. In universities, the transition to virtual teaching and learning has intensified discussions about the relevance and future of regular contact regimes.

Despite the pandemic, we are already living in the era of the Fourth Industrial Revolution (4IR), where cybernetics and computing have entered human life.

In universities, the production of knowledge began to "include a machine way of thinking," - as noted by the philosopher Luciana Parisi [8].

Even in Soviet times, such a branch of psychology as "engineering psychology and pedagogy" began to develop, which explores the processes and means of information interaction between man and machine, as well as between technical means of automation.

In the European Union - the European Commission has adopted an Action Plan on Digital Education [9].

Developed a basic conceptual and theoretical-applied and methodological-instrumental material-book for use in free economic development and development of the university "White Paper: Artificial Intelligence in Higher Education", which describes and identifies opportunities, powers and problems of artificial intelligence in research and teaching, promotes discussion about changes in university teaching, teaching culture and opportunities for teaching and development of educational content in interaction with the use of artificial intelligence in the context of modern neuroscience.

In addition, this material presents a vision for the future of university education and training from the perspective of students and faculty to demonstrate how education and training may change in the coming years due to AI.

When universities argue that 4IR should be given strong and close attention, it means that they can no longer rely only on traditional forms of human thinking and imagination, but also need thinking that depends on algorithmic computations of machines or forms of technology. In this sense, 4IR has changed not only what we do and how we do it, but also who we have become. 
"It's not that cars have replaced humans in the strictest sense, but that people have become embodied in machines.

Thus, we must stop and think carefully about what happens in the educational meeting between teacher and student on separate screens.

We must address the question of human relations in an era of paradoxical strengthening of ties between people [10].

\subsection{Countermeasures and suggestions}

Review of research on this issue, which is now at the forefront not only in robotics and AI (artificial intelligence), but also in - evolutionary genetics, psychology, philosophy, psychiatry, pedagogy, neurology, biochemistry and organic chemistry, microbiology, anthropology, etc. shows that the approach of the interscientific and multidisciplinary community of transhumanists is becoming increasingly important. According to which - if machines (androids, cyborgs, sigmoid, etc.) become capable of feeling and empathy - they will no longer be essentially machines.

Evolution (both natural-biological and organized by man - socio-technologicalintellectual, etc.) will irreversibly lead to the expansion of thinking and endowed with rights and status of new species (along with Homo Sapiens). As the anthropologist, neurologist, biologist Jan Lindbladt called this interspecies community - Homo Sapientissimus [11].

And it is no longer essential - what biological, synthetic, organosilicon, etc., natural or artificial origin will have new species that will entry into the human race.

But in this case, the title and status of "Man" will require even greater relevance and proof of affiliation than today, when it is automatically given by the gamus to biological individuals of the species "Himo Sapiens" of the genus "Homo" (even those quasi-human beings who are guided solely by goals and the needs of instincts and reflexes). The secondary nature of names is precisely what name to give to a phenomenon, and not its essential content.

In addition, mathematical methods in integration with psychological, computer, psychological and social since the 1990s have gone beyond the traditional types of logic, embodied in the so-called "Informal logic", which comprehensively approaches these issues, paying considerable attention to prognostic tasks (in particular, through modeling tools "semantics of probable worlds" J.Hintikka, etc.), problems "language-consciousnessintelligence-society" based on the development of D. Austin, D. Searle, G. Feigl and others. Research in the field of "quantum computers", in particular, is based in its work and from the above.

Under these conditions, people need new knowledge and skills to be able to use new ideas and new technologies and work effectively with them. Given the growing importance of the "human factor", humanistic dimensions come to the first positions in defining higher education strategies for the sustainable development of society [12].

"Transforming our world: the 2030 Agenda for Sustainable Development" - at the global level of education and science offers the following practical mechanism for achieving and providing inclusive, equitable and quality education and training, promoting all opportunities for education and lifelong learning:

- To allow everyone to receive and complete free, fair and quality primary, secondary and higher education, which will lead to appropriate and effective results of sustainable social development of both individual states and the global system.

- Ensure access of all, regardless of social, sexual, racial, ethnic to quality education at all levels, creating appropriate conditions by 2030, which will allow them to successfully move to the next educational levels and carry out lifelong learning. 
- To do this, all levels, models and systems of education ("through education for sustainable development") must be transformed - to acquire the knowledge and skills necessary for sustainable development: sustainable lifestyles, human rights, gender equality, promoting a culture of peace and nonviolence, through global civic education and the recognition of cultural diversity and the contribution of culture to sustainable development.

\section{Conclusion}

The mission of the universities of the XXI century is to form a developed personality, a person of high cultural level, who can act in a situation characterized by significant environmental risks. A freelance graduate who is able to carry out a successful life in such conditions and act as a subject of implementation of guidelines for sustainable development, must have not only and not so much individual professional competencies, but such common qualities as problem-solving ability, critical, independent and original ability of thinking and the ability to generate new knowledge and act in situations of uncertainty and complexity, when knowledge or skills are available, as well as any readymade instructions, are absent or do not function [13].

That is why higher education is able and designed to form a cultural personality and a citizen of a global society capable of living and acting in a world of the XXI century, characterized by uncertainty and risk, is a key factor in implementing the guidelines of sustainable development, their implementation in shared social values, followed by future professionals - both in their professional activities and in everyday life.

\section{References}

1. V. V. Zinchenko, V. V. Levkulych, V. V. Levkulych, and V. Y. Svyshcho, IOP Conf. Ser. Earth Environ. Sci. 635, (2021)

2. J. G. Makin, D. A. Moses, and E. F. Chang, Nat. Neurosci. 23, 575 (2020)

3. J. McCurry, Guard. (2015)

4. I. J. Good, Adv. Comput. (1966)

5. C. Koch, Sci. Am. Mind 26, 26 (2015)

6. R. Cellan-Jones, BBC Newsp. (2014)

7. P. Suciu, Technewsworld (2015)

8. L. Parisi, Technosphere-Magazine (2017)

9. E. Union, Digital Education Action Plan (2021-2027) (2020)

10. N. Davids and Y. Waghid, Teaching, Friendship and Humanity (Springer, . (Briefs in Citizenship Education for the 21st Century, 2020)

11. J. Lindblad, Man Is You, Me and the Primordial (M: Progress, 1991)

12. V. Zinchenko, Int. Sci. J. Univ. Leadersh. 32 (2020)

13. V. V. Zinchenko, Anthropol. Meas. Philos. Res. 50 (2015) 